\title{
Cuando la unión hace la diferencia: rehabilitación de la mano en la Argentina. Un repaso por la historia
}

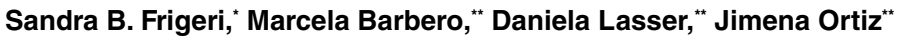 \\ *Terapista Ocupacional, Presidente Institucional del Capítulo Argentino de Terapistas de la Mano, 2020 \\ ${ }^{* *}$ Lic. en Terapia Ocupacional, Vocal, Capítulo Argentino de Terapistas de la Mano, 2020
}

Si bien el nacimiento de la terapia de la mano se remonta a la época de la Segunda Guerra Mundial en Europa, su expansión hacia América fue más tardía.

En la Argentina, en 1997, se concretó la creación del Capítulo Argentino de Terapistas de la Mano (CATM) de la Asociación Argentina de Cirugía de la Mano y Reconstructiva del Miembro Superior (AACM y RMS), ante la necesidad de integrar y nuclear a los distintos profesionales dedicados a la rehabilitación de la mano a lo largo de toda la República Argentina y con el propósito de contribuir al progreso, el estudio, la jerarquización y la enseñanza en el campo de la rehabilitación del miembro superior.

La primera presidenta del Capítulo fue Cristina Alegri, Terapista Ocupacional, reconocida mundialmente por sus contribuciones e innovaciones a las prácticas de la terapia de la mano, quien fue de inspiración para muchos en el desempeño en el área.

En el mismo año, el CATM y la Sociedad Brasileña de Terapistas de la Mano constituyeron la Sociedad Sudamericana de Terapia de la Mano, invitando a Chile y, más tarde, a Bolivia, Colombia y Venezuela, a crear sus respectivas asociaciones y a sumarse a este emprendimiento científico. El CATM fue motivación para Sudamérica.

El desarrollo y la participación científica del Capítulo han ido en crecimiento.

En 2002, el CATM ingresó como Miembro de la Federación Internacional de Sociedades para Terapias de Mano (International Federation of Societies for Hand Therapy, IFSHT) y continúa hasta la actualidad.

En 2004, durante el $6^{\text {th }}$ IFSHT Triennial Congress, en Edimburgo, Escocia, Alegri realiza una presentación memorable sobre el uso de la baba del caracol para el tratamiento de las cicatrices. En reconocimiento a su trayectoria, un importante premio internacional a la innovación en Terapias de Mano que otorga la IFSHT, hoy lleva su nombre.

En 2010, durante el $8^{\text {th }}$ Triennial Congress de la IFSHT, en Orlando, EE.UU., la Argentina gana la postulación para país sede del siguiente Congreso Mundial para cirujanos y rehabilitadores, un hecho de increíble trascendencia.

Así, en 2016, se organizó y desarrolló, por primera vez, en nuestro país y con gran éxito, el $13^{\text {th }}$ IFSSH \& 10th IFSHT Congress, en la Ciudad Autónoma de Buenos Aires, con la participación de importantes referentes mundiales y la presencia de 67 países y 1901 inscriptos. Cabe destacar que este es el evento de mayor relevancia para el Capítulo.

\section{¿En qué consiste la terapia de la mano?}

La "terapia de la mano" es el arte y la ciencia de la rehabilitación de la extremidad superior, que incluye la mano, la muñeca, el codo y el hombro. Formación específica ejercida por Terapistas Ocupacionales, Kinesiólogos, Fisioterapeutas y Terapistas Físicos, combinando un conocimiento integral de la anatomía, la biomecánica, la fisiología, la fisiopatología y la función del miembro superior.

La rehabilitación interdisciplinaria ha producido un corte transversal reemplazando los límites tradicionales entre las dos profesiones.

Recibido el 30-7-2020. Aceptado luego de la evaluación el 31-7-2020 • T.O. SANDRA B. FRIGERI • sanfrigeri28@ gmail.com ID https://orcid.org/0000-0001-5791-8187

Cómo citar este artículo: Frigeri SB, Barbero M, Lasser D, Ortiz J. Cuando la unión hace la diferencia: rehabilitación de la mano en la Argentina. Un repaso por la historia. Rev Asoc Argent Ortop Traumatol 2020;85(Supl.):S40-S44. https://doi.org/10.15417/issn.1852-7434.2020.85.4S.1175 
El propósito de un terapeuta de mano es promover los objetivos de restauración y mantenimiento de la función y la prevención de disfunciones en personas con enfermedades de la extremidad superior, con el fin último de alcanzar un retorno eficiente a sus actividades cotidianas.

La derivación temprana y la comunicación con el médico tratante son la clave para optimizar los resultados del tratamiento, tanto para un tratamiento conservador como posquirúrgico.

El manejo terapéutico de los pacientes con una enfermedad de la extremidad superior, ya sea de tipo neurológica, traumatológica o reumatológica, requiere de un trabajo en equipo.

\section{¿Cómo interviene un terapista de mano?}

El primer contacto con el paciente consta de una entrevista exhaustiva que permitirá recabar información sobre la lesión, el estilo de vida y sus intereses. De acuerdo con los datos obtenidos, se implementará la evaluación a través de diferentes instrumentos específicos con los que cuenta un terapeuta de mano y que permitirán objetivar posteriormente la planificación y evolución del tratamiento (Figura 1).
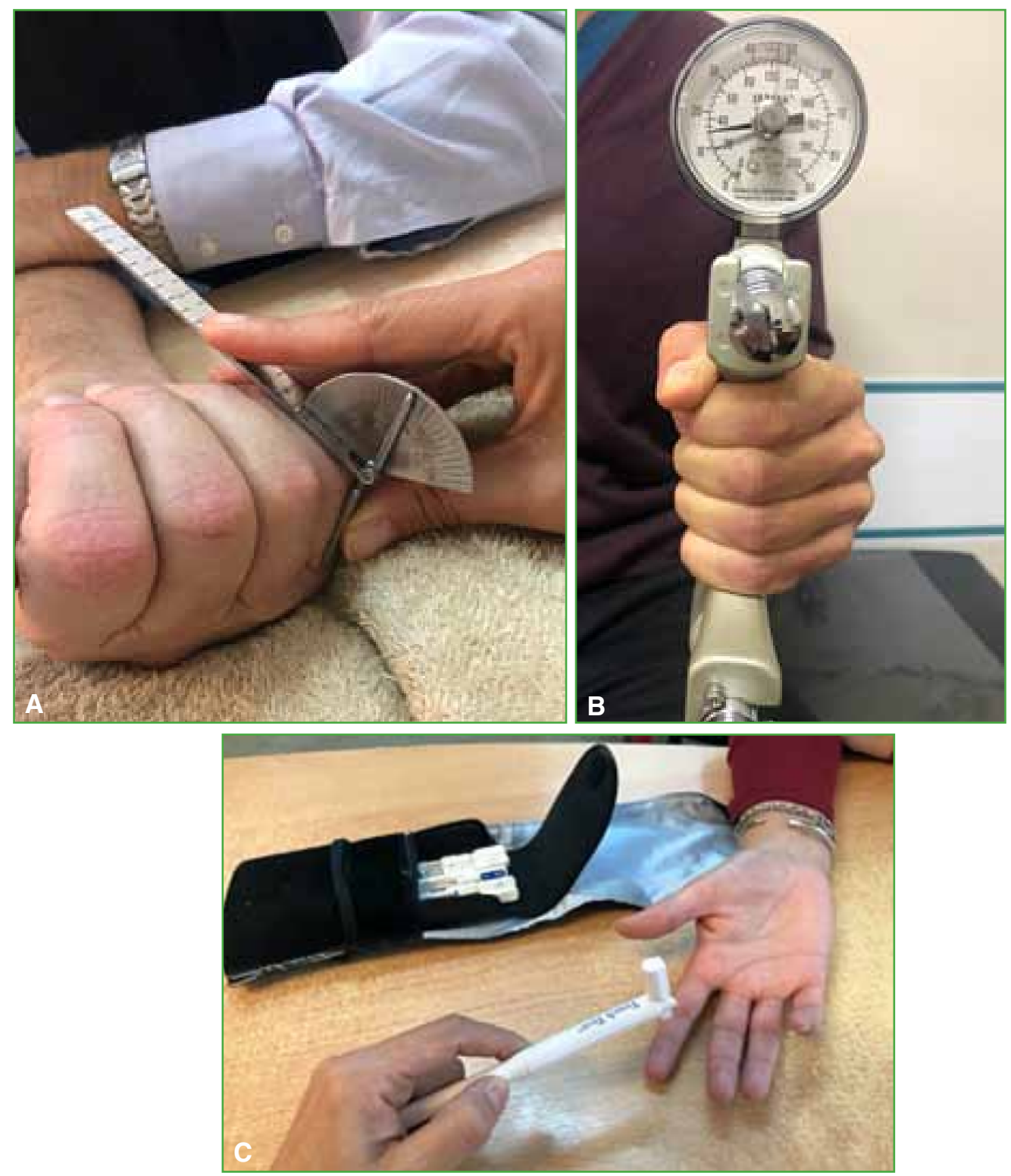

Figura 1. A. Evaluación goniométrica digital. B. Evaluación dinamométrica de la fuerza de puño. C. Evaluación sensitiva. 
De los datos arrojados por la evaluación, surgirán los objetivos de tratamiento, los cuales se irán readaptando a lo largo del proceso terapéutico.

El tratamiento incluye la implementación de diferentes modalidades terapéuticas para alcanzar dichos objetivos (Figura 2):

- Tratamiento del dolor

- Manejo del edema

- Tratamiento de la cicatriz

- Actividades o ejercicios que faciliten la ganancia del rango articular, el aumento de la resistencia, el fortalecimiento, como así también la destreza y coordinación para mejorar la motricidad gruesa y fina

- Entrenamiento de la propiocepción

- Reeducación sensitiva

- Movilización neuronal

- Diseño y confección de ortesis en diferentes materiales

- Asesoramiento y construcción de dispositivos adaptativos y de asistencia

- Modificación ergonómica y técnicas de conservación de la energía

- Asesoramiento y entrenamiento en actividades de la vida diaria
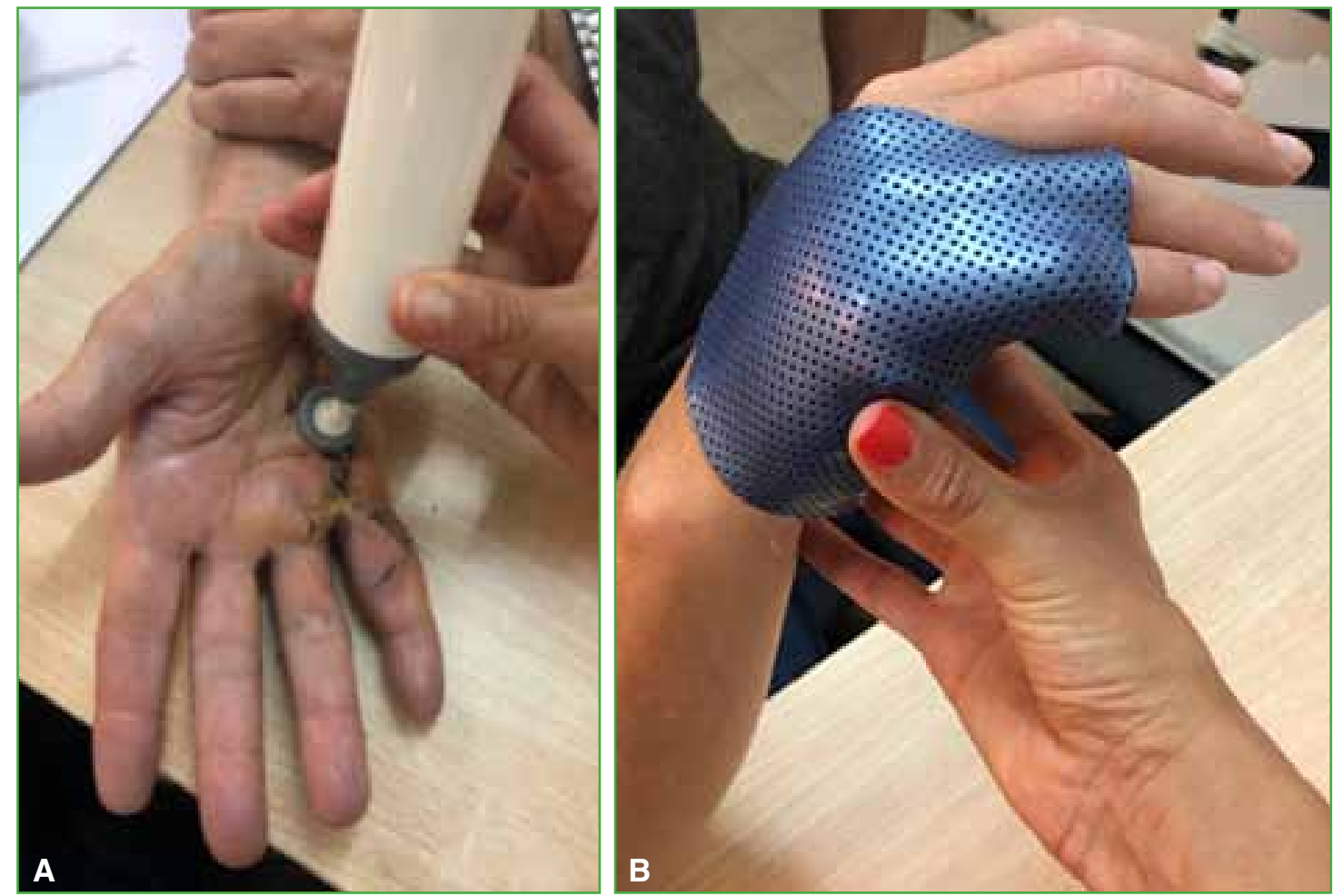

Figura 2. A. Masaje vibratorio en la cicatriz. B. Férula termoplástica de mano en posición intrínseca. 

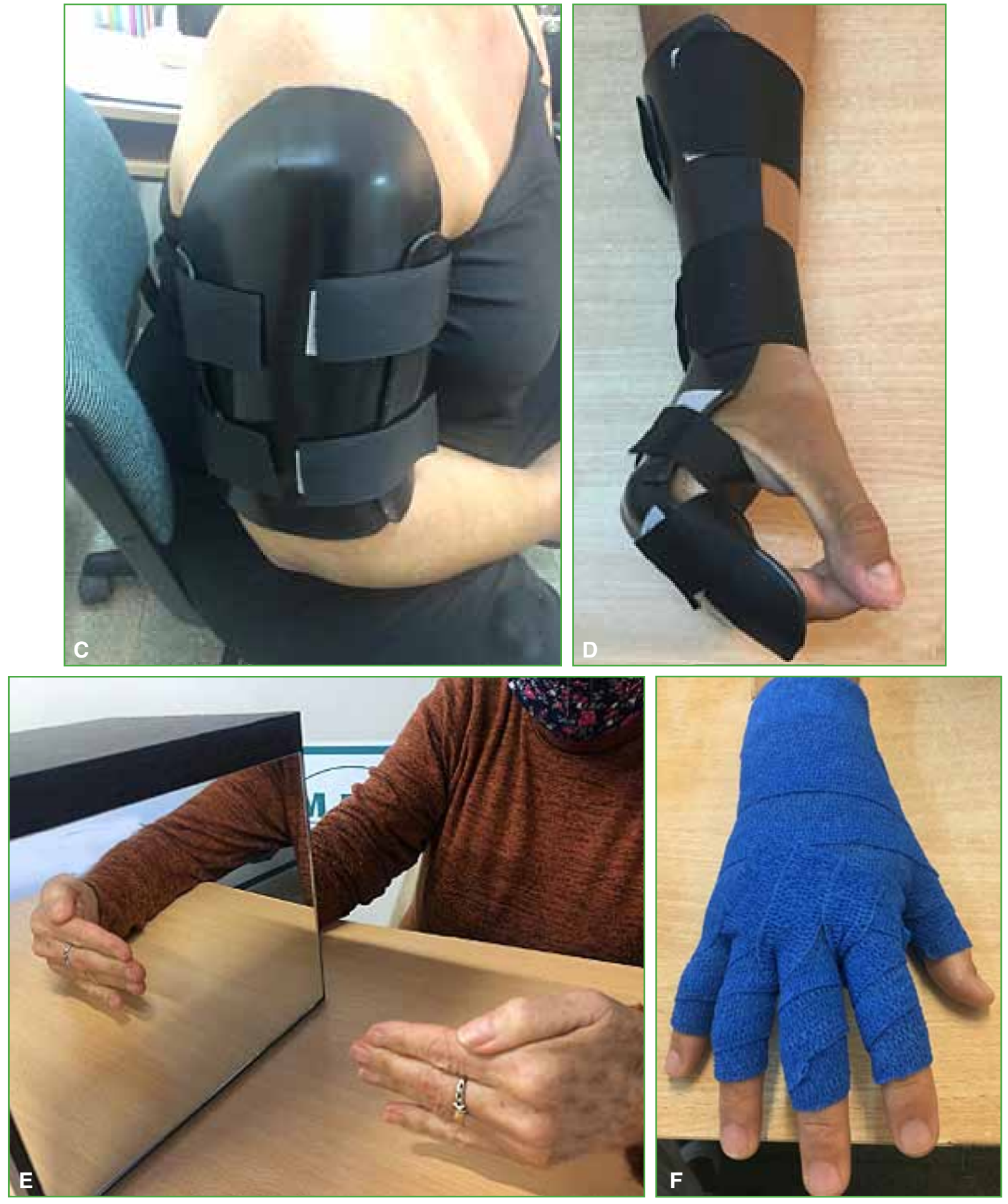

Figura 2. C. Brace humeral. D. Férula termoplástica antebraquidigital en posición intrínseca. E. Terapia de espejo. F. Vendaje corrugado para reducir el edema. 


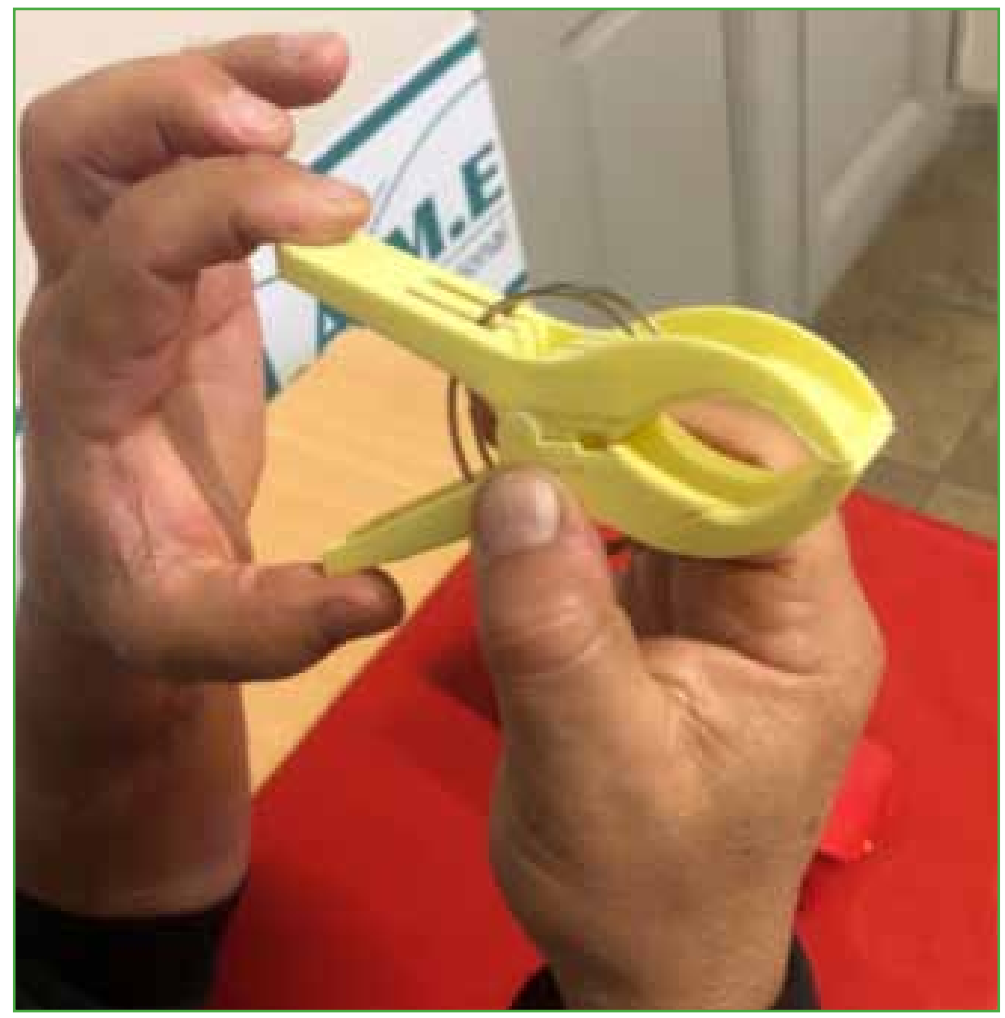

Figura 2. G. Fortalecimiento de pinza digital índice-pulgar. (Las imágenes B, C y D son gentileza de la T.O. Sandra Frigeri.)

El resultado final del tratamiento se verá enriquecido por el vínculo y la empatía establecidos con el paciente. La comunicación y el acompañamiento en todo el proceso potenciarán los resultados.

\section{Atravesando el 2020}

Las distintas comisiones fueron trabajando arduamente año tras año con igual esmero y hoy nos encuentra aquí, en un difícil momento histórico, atravesando una pandemia que nos desafía a continuar con el intercambio y la formación. Gracias a la modalidad virtual hoy se ha logrado llegar, de igual manera, a rehabilitadores de todo el mundo.

Sin duda, el futuro en la Terapia de la Mano vendrá acompañado de los avances en la informática, como también de las tecnologías de la información y comunicación.

Los logros alcanzados hasta la actualidad se los debemos a todos aquellos que, desde los inicios, acompañan el crecimiento del Capítulo, dejando de lado las diferencias y buscando la unión a través del conocimiento y la experiencia.

Juntarse es un comienzo. Seguir juntos es un progreso. Trabajar juntos es un éxito.

\section{Henry Ford}

Conflicto de intereses: Los autores no declaran conflictos de intereses. 